\title{
Synthesis of Model $\mathbf{A}_{5} \mathbf{B}_{1}$ Heteroarm Star Copolymers Using Living Radical Polymerization Mediated by 2,2,6,6-Tetramethylpiperidine-1-oxyl
}

\author{
Eri Yoshida $^{\dagger}$ and Tomoaki Terazono
}

Department of Polymer Science and Engineering, Kyoto Institute of Technology, Goshokaido-cho, Matsugasaki, Sakyo-ku, Kyoto 606-8585, Japan

(Received January 21, 1999)

\begin{abstract}
KEY WORDS $\quad \mathrm{A}_{5} \mathrm{~B}_{1}$ Heteroarm Star Copolymers / 2,2,6,6-Tetramethylpiperidine-1-oxyl / Living Radical Polymerization / Cyclotriphosphazene / Counter Radical / Polystyrene /
\end{abstract}

Considerable attention has been paid to heteroarm star copolymers, since they are expected to promote different microphase segregation from linear block copolymers. There are many publications on heteroarm star copolymers. Rempp et al. found star copolymers of the $\mathrm{A}_{2} \mathrm{~B}_{2}$ type where $\mathrm{A}$ was polystyrene and $\mathrm{B}$ poly $(n$-butyl methacrylate) using divinyl benzene, ${ }^{1}$ while Quirk and his co-workers prepared the $\mathrm{A}_{2} \mathrm{~B}_{2}$ comprising polystyrene and 1,4-polybutadiene using 1,3-bis(1-phenylethenyl)benzene as the core. ${ }^{2}$ Hadjichristidis et al. succeeded in preparing the $\mathbf{A}_{8} \mathbf{B}_{8}$-type of star copolymer using a multi-functional chlorosilane compound. ${ }^{3}$ They have also prepared copolymers of the $\mathrm{ABC}^{4}$ and ABCD types ${ }^{5}$ where $\mathrm{A}$ is polystyrene, B polyisoprene, $\mathrm{C}$ polybutadiene, and $\mathrm{D}$ poly(4-methylstyrene). Isono et al. prepared the $\mathrm{ABC}$ type of copolymer consisting of polystyrene, poly(dimethylsiloxane), and poly( $t$-butyl methacrylate). ${ }^{6}$ Dumas et al. have recently released a publication on the synthesis of a triarm star copolymer comprising polystyrene, poly(ethylene oxide), and poly( $\varepsilon$-caprolactone). ${ }^{7}$ These copolymers were all prepared through living anionic polymerization. The synthesis of the $A_{8} B_{8}$ heteroarm star copolymers through living cationic polymerization has been reported. The copolymer, prepared by Sawamoto et al. comprised two types of poly(vinyl ether). ${ }^{8}$ We found the synthesis of model $A_{5} B_{1}$ copolymers by the radical polymerization using 2,2,6,6-tetramethylpiperidine-1-oxyl (TEMPO) attached to cyclotriphosphazene. Cyclotriphosphazene is a monomer for an inorganic-organic composite polymer with main chains consisting of $\mathrm{P}=\mathrm{N} .{ }^{9}$ This compound is convenient for preparing heteroarm star copolymers, because it is easy to control the number of heteroarms in the star copolymer by choosing the number of TEMPO molecules introduced into cyclotriphosphazene. This paper describes the synthesis of model star copolymers of the $A_{5} B_{1}$ type where $A$ is poly(ethylene oxide) and $B$ polystyrene, through the radical polymerization using TEMPO-supported cyclotriphosphazene as the core.

\section{EXPERIMENTAL}

\section{Measurements}

Gel permeation chromatography (GPC) was per-

\footnotetext{
† To whom correspondence should be addressed.
}

formed with Tosoh HLC-802A equipped with an RI detector and with a Tosoh CP-8000 chromato processor. Two polystyrene gel columns of Tosoh TSK gel G4000 $\mathrm{H}_{8}$ and $\mathrm{G} 2000 \mathrm{H}_{8}$ were used with tetrahydrofuran (THF) as the eluent at $42^{\circ} \mathrm{C}$. ESR spectra were recorded on a Jeol JES-TE 300 ESR spectrometer based on $M_{n}{ }^{2+}$, and ${ }^{1} \mathrm{H}$ NMR spectra were obtained with a Bruker ARX-500 NMR spectrometer. Gas chromatography (GC) was performed with a Shimadzu GC-6A.

\section{Materials}

4-Hydroxy-TEMPO was prepared by the method reported previously. ${ }^{10}$ The oil used for storing the sodium hydride was removed by washing with hexane. Sodium hydride ( $c a .60 \mathrm{wt} \%$ in oil) was suspended in hexane and stirred with a magnetic stirrer at room temperature for $5 \mathrm{~min}$. The hexane was removed by decantation. The bare sodium hydride was dried in vacuo immediately before use. THF was purified by refluxing on sodium for several hours and distilled over sodium. Commercial grade styrene was washed with aqueous alkaline solution and water, and distilled over calcium hydride. Benzoyl peroxide (BPO) was precipitated from chloroform into methanol and recrystallized at $0^{\circ} \mathrm{C}$. Extrapure grade hexachlorocyclotriphosphazene, sodium methoxide, triethylene glycol monomethyl ether, and phenylhydrazine for ${ }^{1} \mathrm{H}$ NMR studies were used without further purification.

Synthesis of 4-Pentachlorocyclotriphosphazoxyl-TEMPO 4-Hydroxy-TEMPO (914 mg, $5.31 \mathrm{mmol})$ dissolved in $10 \mathrm{~mL}$ of THF was added to sodium hydride $(220 \mathrm{mg}$, $9.17 \mathrm{mmol})$ suspended in THF $(4 \mathrm{~mL})$, and the mixture was stirred at room temperature for $1 \mathrm{~h}$ under nitrogen. To a red suspension of 4-sodium oxy-TEMPO was added a solution of hexachlorocyclotriphosphazene $(2.22 \mathrm{~g}$, $6.39 \mathrm{mmol})$ in THF $(10 \mathrm{~mL})$ at $0^{\circ} \mathrm{C}$. The mixture was stirred at $0^{\circ} \mathrm{C}$ for $5 \mathrm{~min}$, kept at room temperature for $23 \mathrm{~h}$, and heated at $50^{\circ} \mathrm{C}$ for the next $115 \mathrm{~h}$. After confirming no spot of 4-hydroxy-TEMPO by TLC, the white precipitate in the mixture was filtered off with suction. The filtrate was concentrated by evaporation, and dried in vacuo for several hours. A crude product $(2.96 \mathrm{~g})$ was obtained. 4-Pentachlorocyclotriphosphazoyl-TEMPO (CPT) was separated by a silica gel column with hexane and then with mixed solvent (benzene : ethyl 
acetate $=50: 1, \mathrm{v} / \mathrm{v}$ ) as the eluent. CPT of $1.44 \mathrm{~g}$ (yield $56 \%$ ) was obtained as red crystals. $m / z=483,328$ $\left(-\mathrm{C}_{9} \mathrm{H}_{17} \mathrm{NO}\right), 312(-\mathrm{O}) . \mathrm{mp}=75^{\circ} \mathrm{C}$.

Synthesis of 4-Pentamethoxycyclotriphosphazoyl-TEMPO Sodium methoxide $(859 \mathrm{mg}, 15.9 \mathrm{mmol})$ was added at $0^{\circ} \mathrm{C}$ to CPT $(1.08 \mathrm{~g}, 2.23 \mathrm{mmol})$ dissolved in $20 \mathrm{~mL}$ of $\mathrm{THF}$, and the mixture was stirred at $0^{\circ} \mathrm{C}$ for $5 \mathrm{~min}$, and kept at room temperature for $12 \mathrm{~h}$ under nitrogen. The white precipitate was filtered off, and the filtrate was concentrated by evaporation. The residue was purified by a silica gel column with a mixed solvent (benzene: ethyl acetate $=50: 1, \mathrm{v} / \mathrm{v})$ to give 4-pentamethoxycyclotriphosphazoyl-TEMPO (MPT) of $0.934 \mathrm{~g}$ (yield 91\%) as red crystals. ${ }^{1} \mathrm{H}$ NMR $\left(\mathrm{CDCl}_{3}\right) \delta 4.55(1 \mathrm{H}, \mathrm{m}, \mathrm{TEMPO}$ $\mathrm{CH}), 3.68\left(15 \mathrm{H}, \mathrm{s}, \mathrm{OCH}_{3}\right), 2.09(2 \mathrm{H}, \mathrm{d}, J=12.6 \mathrm{~Hz}$, $\left.\mathrm{CH}_{2}{ }^{\mathrm{eq}}\right), 1.78\left(2 \mathrm{H}, \mathrm{t}, \mathrm{J}=11.5 \mathrm{~Hz}, \mathrm{CH}_{2}{ }^{\mathrm{ax}}\right), 1.30(6 \mathrm{H}, \mathrm{s}$, $\left.\mathrm{CH}_{3}{ }^{\mathrm{eq}}\right), 1.24\left(6 \mathrm{H}, \mathrm{s}, \mathrm{CH}_{3}{ }^{\mathrm{ax}}\right) \cdot \mathrm{m} / z=462(\mathrm{M}+1), 461,290$ $\left(-\mathrm{C}_{9} \mathrm{H}_{17} \mathrm{NO}_{2}\right) \cdot \mathrm{mp}=58^{\circ} \mathrm{C}$.

Synthesis of 4-Penta[oligo(oxyethylene)]cyclotriphosphazoxyl-TEMPO

Triethylene glycol monomethyl ether $(4.52 \mathrm{~g}, 27.5$ mmol) dissolved in $60 \mathrm{~mL}$ THF was added to sodium hydride $(1.27 \mathrm{~g}, 52.9 \mathrm{mmol})$ suspended in THF $(6 \mathrm{~mL})$, and the mixture was stirred at $0^{\circ} \mathrm{C}$ for $45 \mathrm{~min}$ under nitrogen. To a white suspension of sodium oxytriethylene glycol monomethyl ether was added a solution of CPT $(2.21 \mathrm{~g}, 4.57 \mathrm{mmol})$ in $\mathrm{THF}(30 \mathrm{~mL})$ at $0^{\circ} \mathrm{C}$. The mixture was stirred at $0^{\circ} \mathrm{C}$ for $5 \mathrm{~min}$, and kept at room temperature for $20 \mathrm{~h}$. The white precipitate in the mixture was filtered off with suction. The filtrate was concentrated by evaporation, and dried in vacuo for several hours. 4-Penta[oligo(oxyethylene)]cyclotriphosphazoxyl-TEMPO (OPT) was separated by a silica gel column with ethyl acetate, and then with acetone. OPT of $4.37 \mathrm{~g}$ (yield $85 \%$ ) was obtained as a viscous red liquid. ${ }^{1} \mathrm{H}$ NMR $\left(\mathrm{CDCl}_{3}\right) \delta 4.50(1 \mathrm{H}, \mathrm{m}$, TEMPO $\mathrm{CH})$, $4.30\left(10 \mathrm{H}, \mathrm{s}, \mathrm{POCH}_{2} \mathrm{CH}_{2}-\right), 3.5-3.9\left(50 \mathrm{H}, \mathrm{OCH}_{2}\right)$, $3.37\left(15 \mathrm{H}, \mathrm{s}, \mathrm{OCH}_{3}\right), 2.06\left(2 \mathrm{H}, \mathrm{d}, \mathrm{J}=8.4 \mathrm{~Hz}, \mathrm{CH}_{2}{ }^{\mathrm{eq}}\right)$, $1.72\left(2 \mathrm{H}, \mathrm{t}, J=12.6 \mathrm{~Hz}, \mathrm{CH}_{2}{ }^{\mathrm{ax}}\right), 1.25\left(6 \mathrm{H}, \mathrm{s}, \mathrm{CH}_{3}{ }^{\mathrm{eq}}\right)$, $1.20\left(6 \mathrm{H}, \mathrm{s}, \mathrm{CH}_{3}{ }^{\mathrm{ax}}\right) . \quad m / z=1123(\mathrm{M}+1), 1107(-\mathrm{O})$, $967\left(-\mathrm{C}_{9} \mathrm{H}_{18} \mathrm{~N}\right)$.

Radical Polymerization of Styrene by BPO and TEMPO-Supported Phosphazene: General Procedure

Styrene $(0.5 \mathrm{~mL}, 4.36 \mathrm{mmol})$, BPO $(10 \mathrm{mg}, 0.0413$ $\mathrm{mmol})$, and MPT $(22 \mathrm{mg}, 0.0477 \mathrm{mmol})$ were placed in an ampule. After degassing, the ampule was sealed in vacuo. Polymerization was carried out at first for $3.5 \mathrm{~h}$ at $95^{\circ} \mathrm{C}$, then for $50 \mathrm{~h}$ at $125^{\circ} \mathrm{C}$, and terminated by cooling with liquid nitrogen. The product was dissolved in $5 \mathrm{~mL}$ dichloromethane, purified by repeated precipitation from dichloromethane into hexane, and dried in vacuo for several hours. A polymer $(0.318 \mathrm{~g}$, yield $70 \%)$ was obtained. After the addition of toluene as the internal standard, the dichloromethane solution was subjected to $\mathrm{GC}$ to estimate the conversion of styrene.

\section{RESULTS AND DISCUSSION}

We prepared three TEMPO-supported cyclotriphosphazenes: 4-Pentachlorocyclotriphosphazoyl-TEMPO

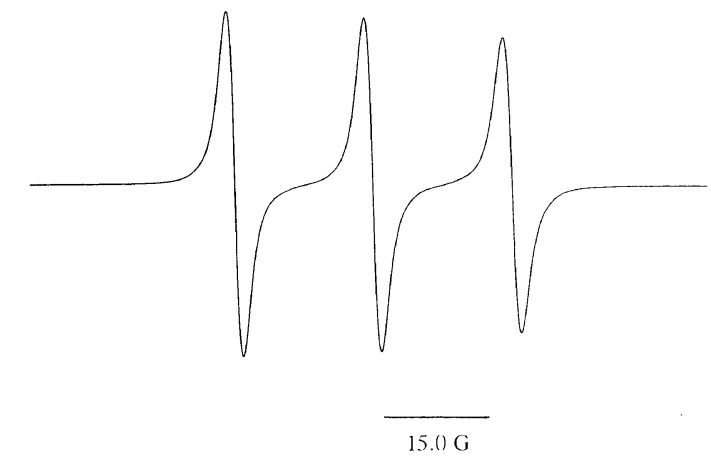

Figure 1. ESR spectrum of OPT (solvent: benzene, at room temperature).

Table I. Characterization of TEMPO-supported cyclotriphosphazenes by ESR

\begin{tabular}{ccc}
\hline PT & \multicolumn{1}{c}{$A_{\mathrm{N}}$} & $g$ \\
\cline { 2 - 3 } & $\mathrm{G}$ & \\
\hline CPT & 15.7 & 2.007 \\
MPT & 15.7 & 2.007 \\
OPT & 15.9 & 2.007 \\
\hline
\end{tabular}

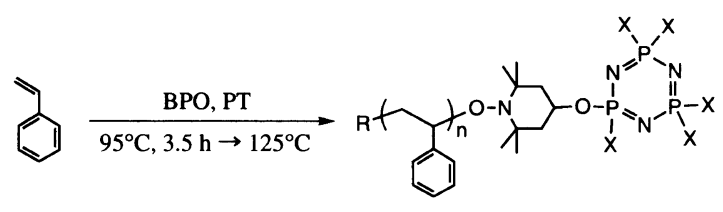

$$
\begin{array}{ll}
\text { CPT: } & X=\mathrm{Cl} \\
\text { MPT: } & X=\mathrm{OMe} \\
\text { OPT: } & X=\mathrm{O}\left(\mathrm{CH}_{2} \mathrm{CH}_{2} \mathrm{O}\right)_{3} \mathrm{CH}_{3}
\end{array}
$$

$\mathbf{R}=$ Benzoyl group or thermal initiator.

Scheme 1.

(CPT), 4-pentamethoxycyclotriphosphazoyl-TEMPO (MPT), and 4-penta[oligo(oxyethylene)]cyclotriphosphazoxyl-TEMPO (OPT). CPT and MPT were obtained as solid crystals, and OPT as a viscous liquid. The compounds were red in color, and showed typical three sharp signals in ESR spectra (Figure 1). Hyperfine coupling constants $\left(A_{\mathrm{N}}\right)$ and $g$ are listed in Table I. The values were close to those of 4-methoxy-TEMPO $\left(A_{\mathrm{N}}=16.0 \mathrm{G}, g=2.007\right)$. This indicates that these phosphazene compounds have the potential to serve as counter radicals for polymerization of styrene, giving polymers with narrow polydispersities, in the same manner as 4-methoxy-TEMPO. Polymerization of styrene was performed in the presence of CPT, MPT, or OPT by BPO as an initiator (Scheme 1). Time-conversion plots are shown in Figure 2. The polymerization by CPT proceeded rapidly in comparison with those by MPT and OPT. This implies that scission occurs more easily when the linkage is between CPT and the growing radical than when it is with MPT and OPT. This may be accounted for by the fact that triphosphazene pentachloride of CPT acts as a Lewis acid for the growing chain end to advance polymerization, when it is taken into consideration that an acid $^{11}$ and organic acid salt ${ }^{12}$ forwards TEMPO-mediated polymerization. Polymer- 


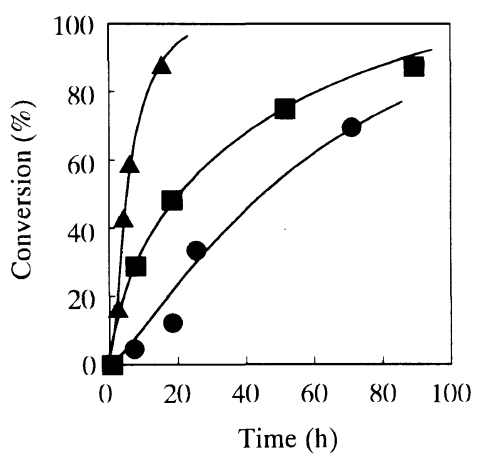

Figure 2. Time-conversion plots for the polymerization of styrene by BPO using CPT $(\boldsymbol{\Delta})$, MPT $(\bullet)$, and OPT $(\boldsymbol{\square})$.

Table II. Conversion, molecular weights, and polydispersity of polystyrenes obtained from CPT, MPT, and $\mathrm{OPT}^{\mathrm{a}}$

\begin{tabular}{|c|c|c|c|}
\hline \multirow{2}{*}{ PT } & Conversion $^{\mathrm{b}}$ & \multirow{2}{*}{$M_{n}{ }^{\mathrm{c}}$} & \multirow{2}{*}{$M_{w} / M_{n}{ }^{c}$} \\
\hline & $\%$ & & \\
\hline \multirow[t]{4}{*}{ CPT } & 17 & 3600 & 1.25 \\
\hline & 43 & 4900 & 1.23 \\
\hline & 58 & 7500 & 1.37 \\
\hline & 88 & 9600 & 1.52 \\
\hline \multirow[t]{4}{*}{ MPT } & 6 & 600 & 1.01 \\
\hline & 14 & 2100 & 1.26 \\
\hline & 35 & 5800 & 1.33 \\
\hline & 71 & 11000 & 1.22 \\
\hline \multirow[t]{4}{*}{ OPT } & 31 & 4000 & 1.11 \\
\hline & 50 & 6900 & 1.23 \\
\hline & 77 & 9900 & 1.19 \\
\hline & 89 & 11000 & 1.21 \\
\hline
\end{tabular}

${ }^{\mathrm{a}}[\mathrm{PT}]_{0} /[\mathrm{BPO}]_{0}=1.1$ in all cases. ${ }^{\mathrm{b}}$ Estimated by GC. ${ }^{\mathrm{c}}$ Estimated by GPC based on polystyrene standards.

ization by OPT is faster than that by MPT. The mobility of the counter radical influenced the rate of polymerization: Bulkiness of the groups on which TEMPO was supported diminished the mobility of TEMPO, causing rate of polymerization to increase. In fact, rate enhancement was observed in styrene polymerization using TEMPO attached to polymers at the chain end. ${ }^{13-16}$ The rate enhancement by OPT probably resulted from restraint on the mobility of TEMPO by supporting it on the phosphazene ring with bulky tetraethylene oxide chains. The relationships between conversion, molecular weight, and polydispersity are shown in Table II. Polydispersities of the polystyrenes obtained from the polymerizations by MPT and OPT were near to or less than 1.3 in the entire region of conversion, while the polymerization by CPT gave rise to the polymers with broad polydispersity. In particular, polydispersity was much broader at the late stage of the polymerization. The molecular weight linearly increased with conversion, suggesting that the polymerization proceeds in accordance with a living mechanism. Relationship between molecular weight and initial concentration of the counter radicals $\left([\mathrm{PT}]_{0}\right)$ was also studied. This investigation is based on our previous results that molecular weight is in proportion to the reciprocal of the initial concentration of TEMPO if the polymerization proceeds in a living manner. The relations are shown in Table III. Conversions were high enough to
Table III. Relationship between molecular weight and $[\mathrm{PT}]_{0}$

\begin{tabular}{|c|c|c|c|c|c|}
\hline \multirow{2}{*}{ PT } & {$[\mathrm{PT}]_{0}$} & Time & Conversion $^{\mathrm{a}}$ & $M_{n}^{\mathrm{b}}$ & \multirow{2}{*}{$M_{w} / M_{n}^{\mathrm{b}}$} \\
\hline & $\times 10^{2} \mathrm{~mol} \mathrm{~L}^{-1}$ & $\mathrm{~h}$ & $\%$ & $\times 10^{-4}$ & \\
\hline \multirow[t]{4}{*}{ CPT } & 3.21 & 21 & 82 & 3.2 & 1.58 \\
\hline & 4.63 & 25 & 100 & 2.3 & 1.64 \\
\hline & 9.60 & 48 & 93 & 1.6 & 1.54 \\
\hline & 19.2 & 70 & 100 & 1.1 & 1.43 \\
\hline \multirow[t]{4}{*}{ MPT } & 1.95 & 47 & 89 & 2.2 & 1.32 \\
\hline & 2.38 & 50 & 76 & 1.9 & 1.25 \\
\hline & 4.77 & 70 & 71 & 1.1 & 1.22 \\
\hline & 9.54 & 141 & 93 & 0.92 & 1.27 \\
\hline \multirow[t]{4}{*}{ OPT } & 3.21 & 39 & 88 & 3.8 & 1.24 \\
\hline & 4.63 & 65 & 84 & 2.4 & 1.22 \\
\hline & 9.60 & 50 & 77 & 0.99 & 1.19 \\
\hline & 18.9 & 86 & 88 & 0.76 & 1.24 \\
\hline
\end{tabular}

${ }^{\mathrm{a}}$ Estimated by GC. ${ }^{\mathrm{b}}$ Estimated by GPC based on polystyrene standards.

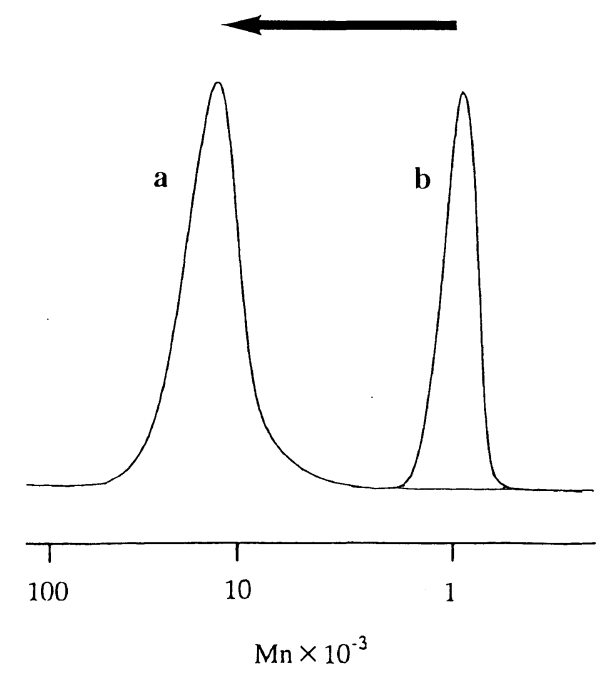

Figure 3. GPC profiles of polymers obtained (a) and OPT (b).

compare molecular weights. Molecular weights were in inverse proportion to $[\mathrm{PT}]_{0}$. All the polymerizations thus undoubtedly proceed in accordance with a living mechanism. The entirety of the TEMPO-supported triphosphazenes was engaged in the polymerizations, because GPC of the resulting polymers showed no peak in the field of the phosphazene compounds. Figure 3 shows GPC of OPT and the resulting polymer before isolated. Observation of unimodal GPC originating from the polymer was made only on the higher molecular weight side. ${ }^{1} \mathrm{H}$ NMR analysis clarified that the polymers have the TEMPO-supported triphosphazenes and benzoyl group. The spectrum of the polymer obtained from OPT is shown in Figure 4. Signals at 7.5 and $7.9 \mathrm{ppm}$ are due to benzoyl group, assigned to aromatic protons at meta and ortho positions, respectively. The signals at $0.2,0.4,0.9$, and $1.1 \mathrm{ppm}$ are attributed to tetramethyl protons of TEMPO. Observation of signals based on tetraethylene oxide was also made at $3.3-4.1 \mathrm{ppm}$. The sharp signal at $3.35 \mathrm{ppm}$ was assigned to terminal methoxy group, and the signals at 3.55 and $3.68 \mathrm{ppm}$ to the methylenes. The signal at $4.00 \mathrm{ppm}$ is attributed to another oxymethylene attached to the phosphazene ring. The protons of the polystyrene terminal methine bonded to TEMPO moiety 


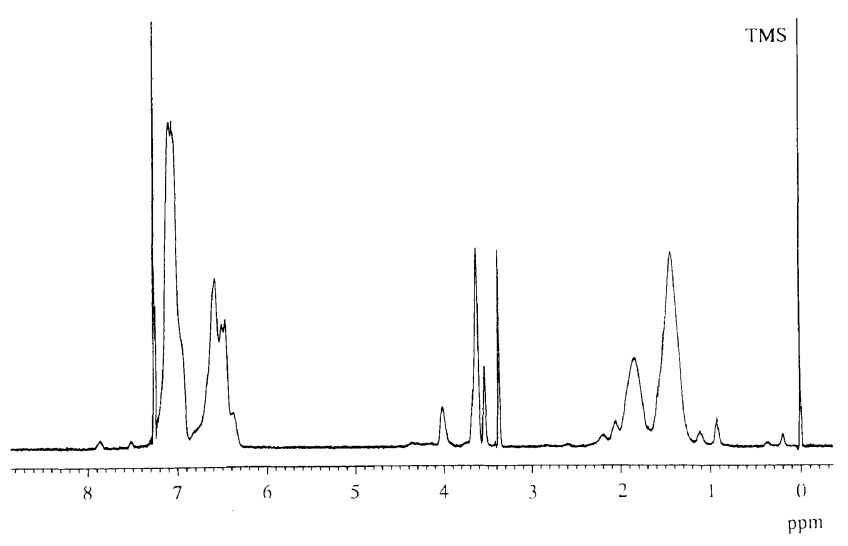

Figure 4. ${ }^{1} \mathrm{H}$ NMR spectrum of the polymer (conversion $=50 \%$, $M_{n}=6900$, and $M_{w} / M_{n}=1.23$ ) obtained from OPT. Polymerization was carried out at $125^{\circ} \mathrm{C}$ for $18 \mathrm{~h}$, after being held at $95^{\circ} \mathrm{C}$ for $3.5 \mathrm{~h}$ (solvent: $\mathrm{CDCl}_{3}$ ).

and of the methylene attached to benzoyl group are observed at 3.8-4.4 ppm as broad signals. Polystyrene should have a cyclotriphosphazene moiety at the chain end, and the model compounds of a $\mathrm{A}_{5} \mathrm{~B}_{1}$ star copolymer comprising poly(ethylene oxide) and polystyrene were obtained.

\section{CONCLUSIONS}

The synthesis of model $\mathrm{A}_{5} \mathrm{~B}_{1}$ heteroarm star copolymers comprising poly(ethylene oxide) and polystyrene was conducted by the radical polymerization using TEMPO-supported cyclotriphosphazene. The polymerization rapidly occurred by the presence of CPT, although the polymers obtained had broad polydispersity. MPT and OPT gave polymers with narrow polydispersity $(<1.3)$. The polymerization proceeded in accordance with a living mechanism, because the molecular weight was in proportion to conversion and reciprocal of the initial concentration of the counter radicals. The polymers were obtained in quantitative efficiency based on GPC. ${ }^{1} \mathrm{H}$ NMR analysis demonstrated that the polymers had the cyclotriphophazene moieties at a chain end, and that model $\mathrm{A}_{5} \mathrm{~B}_{1}$ star copolymers were obtained.

\section{REFERENCES}

1. C. Tsitsilianis, P. Chaumont, and P. Rempp, Makromol. Chem., 191, 2319 (1990).

2. R. P. Quirk, T. Yoo, and B. Lee, J.M.S.-Pure Appl. Chem., A31, 911 (1994)

3. A. Avgeropoulos, Y. Poulos, N. Hadjichristidis, and J. Roovers, Macromolecules, 29, 6076 (1996).

4. H. Iatrou and N. Hadjichristidis, Macromolecules, 25, 4649(1992)

5. H. Iatrou and N. Hadjichristidis, Macromolecules, 26, 2479(1993)

6. T. Fujimoto, H. Zhang, T. Kazama, Y. Isono, H. Hasegawa, and T. Hashimoto, Polymer, 33, 2208 (1992).

7. O. Lambert, P. Dumas, G. Hurtrez, and G. Riess, Macromol. Rapid Commun., 18, 343 (1997).

8. S. Kanaoka, T. Omura, M. Sawamoto, and T. Higashimura, Macromolecules, 25, 6407 (1992).

9. H. R. Allcock, J. A. Dodge, I. Manners, and G. H. Riding, J. Am. Chem. Soc., a, 113, 9596 (1991).

10. T. Kurosaki, K. W. Lee, and M. Okawara, J. Polym. Sci., Polym. Chem., 10, 3295 (1972).

11. M. K. Georges, R. P. N. Veregin, P. M. Kazmaier, G. K. Hamer, and M. Saban, Macromolecules, 27, 7228 (1994).

12. P. G. Odell, R. P. N. Veregin, L. M. Michalak, D. Brousmiche, and M. K. Georges, Macromolecules, 28, 8453 (1995).

13. E. Yoshida and A. Sugita, Macromolecules, 29, 6422 (1996).

14. E. Yoshida and M. Nakamura, Polym. J., 30, 915 (1998).

15. E. Yoshida and Y. Osagawa, Macromolecules, 31, 1446 (1998).

16. E. Yoshida and A. Sugita, J. Polym. Sci., Polym. Chem. Ed., 36, 2059 (1998). 